\title{
Volunteers trained in palliative care at the hospital: An original and dynamic resource
}

\author{
SYLVETTE DELALOYE, M.A., ${ }^{1}$ MONICA ESCHER, M.D. ${ }^{1}$ CHRISTOPHE LUTHY, M.D., ${ }^{2}$ \\ VALÉRIE PIGUET, M.D., ${ }^{1}$ PIERRE DAYER, M.D., ${ }^{1}$ AND CHRISTINE CEDRASCHI, PH.D. ${ }^{1,2}$ \\ ${ }^{1}$ Division of Clinical Pharmacology and Toxicology, Consultation for Pain and Palliative Care Center, University \\ Hospitals of Geneva Faculty of Medicine, Geneva, Switzerland \\ ${ }^{2}$ Division of General Medical Rehabilitation, University Hospitals of Geneva Faculty of Medicine, Geneva, Switzerland \\ (RECEIved November 14, 2013; ACCEPTED January 11, 2014)
}

\begin{abstract}
Objective: Volunteers trained in palliative care are increasingly present in acute care units in general hospitals. Nevertheless, there still are few available data on this topic, especially concerning the integration of volunteers outside the palliative structures. Our present study aimed to describe the experience of volunteers trained in palliative care in the context of a primary care hospital. In particular, the difficulties and the benefits of this specific position were evaluated according to volunteers' own perceptions and words.

Method: We employed a qualitative method. Various aspects of the volunteer's role were explored by means of semistructured questions, addressing their activity, their motivations, and their feelings. Participants were volunteers $(n=19)$ trained in palliative care and working at a university hospital. After giving written consent, they completed the semistructured questionnaire at home. Content analysis was used to identify the main categories of answers and the principal themes reported by the volunteers.

Results: The main difficulties were related to uncertainty of the context. As every situation is different, volunteers could not define their role once and for all. However, they derived great satisfaction from their activity. A supporting frame and a good balance between constraints and autonomy were facilitating factors. Besides, the complexity related to the context contributed to make the position valuable and challenging.

Significance of results: Integrating a voluntary service in a primary care hospital is partly based on active participation of the volunteers in developing their position in a more adequate way. In return, this relative autonomy implies a rigorous and supportive attitude from the institution.
\end{abstract}

KEYWORDS: Palliative care volunteers, Role identification, Volunteer satisfaction, Palliative and supportive care, General hospitals

\section{INTRODUCTION}

Voluntary work in palliative care has always played an important role in supporting patients and promoting quality of life in hospices (Fusco-Karmann \& Tinini, 2001; Sterchi-Noden, 2007; Morris et al., 2013). The role and contribution of volunteers in

Address correspondence and reprint requests to: Sylvette Delaloye, Multidisciplinary Pain and Palliative Care Center, Division of Clinical Pharmacology and Toxicology, University Hospitals of Geneva, 4 rue Gabrielle-Perret Gentil, 1211 Geneva 14, Switzerland. E-mail: Sylvette.Delaloye@hcuge.ch this specific domain have been reported throughout the literature (e.g., Doyle, 2002; McKinnon, 2002; Andersson \& Ohlen, 2005; Wilson et al., 2005). Although the appeal of voluntary work varies in different countries and types of institutions, it has been growing. Palliative care volunteers are present in various institutions of care, particularly in general hospitals (Doyle, 2002; Delaloye, 2007; Künzi, 2007).

The vocation of volunteers trained in palliative care includes giving of their time and presence, and listening to patients. This work provides help on different levels. First, it makes it possible to 
maintain "social capital" for a hospitalized person and allows the end of life to not be confined within a medical or professional context (McKinnon, 2002). Volunteers also bring comfort on a psychological level, by listening to the existential questionings, particularly when patients face the anguish of illness and death (Mouniqua, 2006; Sévigny et al., 2010). Volunteers, who are not caregivers per se, also help to maintain the views that patients are first and foremost persons and that their identity is not confined within their illness (Landry-Dattée, 2000; Künzi, 2011).

In a more concrete way, several studies have shown the significant contribution of volunteers to patients' quality of life (Handy \& Srinivasan, 2002; Wilson et al., 2005; Block et al., 2010). In particular, they bring the kind of social support that improves the well-being of patients (Brazil \& Thomas, 1995; Musick \& Wilson, 2003). These benefits are extended to institutions other than hospices and not only to patients in palliative care. For example, there are much data that stress the importance of considering the existential needs of patients who suffer from cancer and who are confronted with their own death (Macvean et al., 2007; Ernstmann et al., 2009; Moadel et al., 1999; Nissim et al., 2009).

Though volunteers trained in palliative care are deeply involved in the field of healthcare, there is little available research and data concerning their presence outside the palliative structures. To our knowledge, no study specifically dedicated to volunteering in the context of primary care hospitals has been reported before now. The original objective of our study was to describe the specific experience of being a palliative care volunteer in a primary care hospital. It was focused on identification of the difficulties and benefits of this position and the factors that may favor integration of volunteers in this specific context, according to volunteers' own perceptions.

\section{METHODS}

A qualitative observational study was carried out to allow volunteers to express themselves on their position and to describe its characteristics in terms of their own experience and representations, as well as in terms of their activities. The protocol was approved by the local ethics research committee, and all participants signed a written consent form before being included in the study.

\section{Setting and Population}

The study was conducted at the University Hospitals of Geneva, an urban public and teaching hospital, which is the major primary care hospital in its area. A team of volunteers trained in palliative care has been active there since 1997. This team is related to the hospital's Multidisciplinary Pain and Palliative Care Center. The team is coordinated by a psychologist from the center who also provides teaching and supervision. Nineteen volunteers work in the different care units in surgery, internal medicine, and rehabilitation. These care units chose to collaborate with volunteers in order to offer support to their patients. Volunteers visit the patients twice a week, always in the same care units. The great majority of visited patients suffer from cancer or such chronic and progressive illnesses as severe diabetes and neurological disorders.

All volunteers were informed orally by the coordinator about the aims of our study and the modalities of participation. They then received the written information. All of them (19 in total) agreed to participate and returned the signed written consent. They completed a semistructured questionnaire at home and returned it by post to a member of the research team independent of the group of volunteers.

\section{Instruments}

Our semistructured questionnaire was designed specifically for the purposes of this study, since no instrument was available to explore the domains the study was set up to investigate. A pilot phase allowed for testing the questionnaire with three former volunteers who were not involved in the study.

The questionnaire included thirty-three questions investigating the course of the volunteers, their motivations, representations, satisfaction, and difficulties. It aimed to determine how the volunteers viewed their activity and also to appraise the sense and the value they attributed to their role. Sociodemographic characteristics were also recorded. The participants could choose not to respond to these questions if they wanted to further ensure their anonymity. The majority of the questions were open ended in order to limit constraints and more fully gain access to participants' way of thinking.

Evaluation scales were also proposed, dealing with the following topics:

- satisfaction with the position and with how they had been welcomed into the group of volunteers and in the wards (from $0=$ not at all satisfied, to $10=$ most satisfied)

- congruence of volunteering work with their expectations (from $0=$ does not at all correspond, to $10=$ corresponds totally)

- feeling of recognition (from $0=$ not at all recognized, to $10=$ fully recognized) 
- feeling of utility (from $0=$ no utility, to $10=$ great utility)

As the coordinator was a member of the research group, we paid particular attention to the anonymity of the data. Envelopes containing completed questionnaires were sent by post and opened by a member of the research team independent of the group of volunteers. Participants' responses were further checked for anonymity before being submitted for content analysis. Therefore, all responses were typed, and the demographic data were analyzed separately.

\section{Analysis}

Data analysis was performed by two psychologists trained in content analysis procedures (Blanchet et al., 1987; Mays \& Pope, 1995; Pope et al., 2000). As for the evaluation scales, mean and median scores were calculated (Table 2). As for open-ended questions, a posteriori categories were defined, drawing from the responses of volunteers. A grid was elaborated for each question and systematically augmented following a constant comparison method. In the first step, categories were defined according to the responses until the grid was saturated, that is, until all responses to each question could be listed in the grid. In the course of the analysis, categories confirmed by the data were kept while others were broadened to account for the whole set of participant responses. The analysis of these categories was then progressively refined, from a purely descriptive categorization of the data to a more global and abstract one, in order to bring to light the salient elements of volunteers' responses and thus account for the key aspects of their experience. This refinement was conducted through several steps of comparison, synthesis, and thematic grouping between the various analysis grids. These steps contributed to the final definition of the themes that account for the personal experience the volunteers described in their responses. Furthermore, an index of responses particularly representative of the various themes was established.

Table 1. Volunteers' demographic characteristics $(\mathrm{N}=19)$

\begin{tabular}{lc}
\hline Age, mean $(\min , \max )$ & 56 years $(40,73)$ \\
Gender, $n(\%)$ & 16 female $(84) / 3$ \\
& male $(16)$ \\
Working as volunteers in this & 3 years $(6$ months $/$ \\
$\quad$ hospital, mean $(\min / \mathrm{max})$ & 12 years $)$ \\
$\begin{array}{l}\text { Working as volunteers elsewhere, } \\
\quad n(\%)\end{array}$ & $11(58)$ \\
Not professionally active, $n(\%)$ & $13(68)$
\end{tabular}

Table 2. Volunteers' satisfaction degree (on a scale from 0 [not satisfying at all] to 10 [very satisfying])

\begin{tabular}{lc}
\hline \hline Criterion & $\begin{array}{c}\text { Mean Degree } \\
\text { (Median) }\end{array}$ \\
\hline Quality of welcome in volunteer team & $9(10)$ \\
Quality of welcome in wards & $8(8)$ \\
Satisfaction degree with the activity & $9(9)$ \\
Satisfaction degree compared to & $9(9)$ \\
$\quad$ expectations & \\
Feeling acknowledged & $8.5(9)$ \\
Feeling useful & $8(8)$ \\
\hline \hline
\end{tabular}

\section{RESULTS}

All 19 volunteers completed the semistructured questionnaire. The characteristics of the participants are presented in Table 1.

Content analysis of volunteer responses provided three themes that encompassed:

- the identity of volunteering

- the qualities and utility of volunteering at the hospital

- the dynamic of integration

\section{THE IDENTITY OF VOLUNTEERING}

\section{A Positive and Rewarding Identity}

Volunteers expressed a high level of satisfaction with regard to their activity, as shown in the results of the evaluation scales (Table 2). This satisfaction was described as the result of highly diverse and meaningful encounters. Many volunteers described their position as a privilege and generally considered that they received more than what was asked from them:

I had only few expectations (. . .) but since I have this position, I experience a kind of an accomplishment. I feel a great satisfaction; it is almost a silent communion with them. I have the feeling I found the goal of my life. (volunteer 4)

What's motivating me is the passion of meeting the other, even if he or she is unknown to methe desire to give friendship to others. At every encounter, I have the feeling of gaining insight into human universes, always fascinating and never the same. (volunteer 6)

\section{A Changing and Complex Identity}

Although experienced very positively, the position of volunteer was also characterized as complex. This complexity was expressed in three main ways: 
- the difficulty to integrate and explain one's role within the healthcare team and with patients

- the difficulties related to the necessity of constant adaptation to the shifting context of acute care wards (short hospitals stays, shifts in the team, lack of intimacy in the rooms)

- the difficulty to define precisely and definitively the limits of the position of volunteer

The following account illustrates the various aspects of this complexity:

Volunteering goes way beyond what I expected. There is no limit in this field. On each visit, I discover something new that I would never have imagined. (...) What I find a bit complicated is that the healthcare team changes all the time, so that I am always dealing with new people. There is an incredible coming and going. (volunteer 10)

\section{THE QUALITIES AND UTILITY OF VOLUNTEERING AT THE HOSPITAL}

\section{Qualities of the Volunteers}

The position and the skills of supporting volunteers are difficult to precisely define. One of the volunteers described them in these terms:

A certain concentration ability is necessary to forgetfulness of self in order to better be in empathy with the person the volunteer visits. (volunteer 6)

When asked to describe the qualities necessary for their function, volunteers emphasized the ability to listen to and empathize with patients. Nevertheless, the quality of support was essential in their relationships with patients:

I don't know by what miracle there is a movement or a word coming to me, and that allows me to get in touch with the person. Then I listen (. . .) I often have the feeling to be a feather that lands on the edge of a bed; it takes the mind off things. It's entertaining. (volunteer 10)

\section{Usefulness of Volunteering}

In general, volunteers get little feedback regarding the possible benefits of their interventions, be it from care providers or even more from patients, whose hospital stay is often very short. This did not prevent volunteers from feeling globally useful: on average, this feeling was rated at 8 on a 10-point scale (see Table 2). The value in volunteering lay mainly in how volunteers viewed the patients, that is, a nonnursing view and a relationship in which the disease was not alone in the forefront and where a kind of lightness could even take place. The following account illustrates this point:

There is a lot of loneliness, of anxiety and fears; we can help the patients through our presence, reassure them, give them back their dignity, and encourage them. I think I bring a little happiness, a little bit of the external world, a breath of fresh air. Some patients are worried about us. They ask us many questions. They need to participate in everything that happens, they are alive. (volunteer 18)

\section{THE DYNAMIC OF INTEGRATION}

\section{The Importance of Setting: Rigorous but not Rigid}

The rigorous setting and the numerous constraints on their appointment (contract, job specifications, training) contributed to the group identity. These elements convey clarity, milestones, and limits to a position involving many uncertainties. However, although volunteering in the context of acute care requires a strict dependency toward various instructions, it also necessitates autonomy and spontaneity. Within the setting, a certain amount of variation has thus to be favored and supported in the exercise of volunteering. The following description reported accurately on this contrast:

To be a member of a structured team of volunteers, well-organized, supervised, and motivated belonged to my expectations, and this is what I found at the Geneva University hospitals. (. . .) Introduction [in the care unit] was fine. It is rather in the follow-up that it becomes more difficult. After the greetings and presentations, I'm left to myself. You have to try to understand by yourself how the care unit works. This activity requires some independence of mind and of movement. (volunteer 19)

\section{The Feeling of Membership}

While institutional acknowledgment was important, belonging to a well-defined group, with its rules, but also with the exchanges it allows, constituted a major criterion of satisfaction. The quality of the welcome, the support, and the user-friendliness of the group were often pointed out by volunteers as essential features:

I have the impression I always belonged to the group of volunteers. (volunteer 5) 
What I appreciate most are human contacts, with my volunteer colleagues as well, the very strong feeling of belonging to a group. (volunteer 9)

\section{Feeling Acknowledged and Useful}

While the position of the volunteers was often experienced as rewarding, it may not have been explicitly acknowledged and valued by the various partners. The workload of the care providers and the frequent shifts in the care units and in the patients led to a feeling of invisibility, as one volunteer noted:

(. . .) to accept this impression of uselessness, the difficulty to appraise the effects of the visit for the patients. Only the patients have to be the focus of our interest. (volunteer 19)

The complexity and ever-changing characteristics of the context clearly made for elements hard to overcome. It was also the major source of frustrations. However, these difficulties were also perceived as a challenge, which when taken up contributed to the value of volunteering:

It takes time to become integrated. (...) What I like most is the complicity and discussions I can have with the healthcare team. We help each other by exchanging our feelings and what we could do for the patient's well-being. It is often very constructive. (volunteer 18)

\section{DISCUSSION}

Our study emphasized two major findings concerning the presence of palliative care volunteers in a primary care hospital.

The first point concerns the experiences of volunteers. On the whole, volunteers reported a positive view of their position. They took great satisfaction from their work and described it as challenging, rewarding, and useful. These results are consistent with the literature on volunteering in hospice and palliative care (Field \& Johnson, 1993; Doyle, 2002; Andersson \& Ohlen, 2005; Claxton-Oldfield \& Claxton-Oldfield, 2008a; Guirguis-Younger \& Grafanaki, 2008). According to the definition of Gagnon and Sévigny (2000), volunteering can be considered a privileged moment for recognition of oneself and others. What volunteers want above all is to carry out significant and rewarding actions. The second point concerns the factors likely to promote adaptation of volunteers in a context of general care. Interestingly, the complexity and uncertainties of the environment were experienced as a challenge by volunteers. This seemed to contribute to increased role status. Diffi- culties were seen as bringing value and meaning to their work.

Volunteer work is expected to become more important in the field of healthcare. Our study raises some interesting issues in this perspective. Two points should be particularly emphasized in this regard. First, content analysis stressed the importance of the dynamic of integration and in particular of the setting of the volunteer group. This framework should be rigorous but not rigid. It should provide ongoing support to volunteers, clear rules, and strong values. On the other hand, it should be flexible enough to allow spontaneous meetings and a kind of "natural helping," as described by Guirguis-Younger et al. (2005). As mentioned by several authors, volunteer work, particularly in a professional context, must be precise, punctual, demanding, and developmental (Merrel, 2000; Künzi, 2007; Claxton-Oldfield \& Claxton-Oldfield, 2008b; Sévigny et al., 2009).

Second, in terms of adaptation, it seems more effective to help volunteers to cope with the complexity of a context rather than trying to reduce the difficulties. This issue was also documented in a study investigating the complexity of roles and boundaries of volunteering in well-woman clinics (Merrel, 2000) Other studies pointed out that integration of volunteers should be seen as a dynamic and developing process (Guirguis-Younger et al., 2005; St,-Pierre et al., 2009; Papadaniel, 2010).

Therefore, integrating a volunteer service in the context of a primary care hospital is partly based on the active participation of volunteers in developing their position in a more adequate way. In return, this relative autonomy implies a supportive attitude from the institution, especially throughout supervision and learning sessions (Doyle, 2002; Andersson \& Öhlen, 2005; Künzi, 2007).

\section{LIMITATIONS OF THE STUDY}

Our study has its limitations. The written responses to the semistructured questionnaire limit the probes that might help in finding deeper insights or formulating better questions. Our sample was small, though the frequency of repetitive statements suggests that extending our inquiry would not have produced very different concerns. In addition, the responses from our sample allowed for an approximation of the range of possible responses and to achieve theoretical saturation in this specific context of investigation. The transferability of the responses of volunteers collaborating in acute and subacute settings is another limit. However, as for the difficulties and challenges they actually expressed, they overlapped with those conveyed in numerous studies involving palliative care volunteers and with different 
methods of investigation (Andersson \& Ohlen, 2005; Claxton-Oldfield \& Claxton-Oldfield, 2008a; Guirguis-Younger \& Grafanaki, 2008; Papadaniel, 2010).

\section{CONCLUSION}

We found that volunteering in a general hospital is seen as a rewarding and challenging activity. Our data are consistent with those reported in other studies with volunteers working in palliative care units and hospices. They indicate that volunteers trained in palliative care have their place in acute and general care settings. The study constitutes a first contribution to better understand the potential benefits and specificities of volunteer work in this particular context. It brings together lines of thinking to improve the integration of volunteers and to define an adequate framework. These results are promising considering the potential growth in palliative care volunteering in various settings.

\section{ACKNOWLEDGMENTS}

We are grateful to all the volunteers who agreed to share their experience and contribute to our study.

\section{CONFLICT OF INTEREST STATEMENT}

The authors have no conflicts of interest to declare.

\section{REFERENCES}

Andersson, B. \& Ohlen, J. (2005). Being a hospice volunteer. Palliative Medicine, 19, 602-609.

Blanchet, A., Ghiglione, R., Massonat, J., et al. (1987). Les techniques d'enquête en sciences sociales. Paris: Dunod.

Block, E.M., Casarett, D.J., Spence, C., et al. (2010). Got volunteers? Association of hospice use of volunteers with bereaved family members' overall rating of the quality of end-of-life care. Journal of Pain and Symptom Management, 39, 502-506.

Brazil, K. \& Thomas, D. (1995). The role of volunteers in a hospital-based palliative care service. Journal of Palliative Care, 11, 40-42.

Claxton-Oldfield, S. \& Claxton-Oldfield, J. (2008a). Some common problems faced by hospice palliative care volunteers. American Journal of Hospice \& Palliative Medicine, 25, 121-126.

Claxton-Oldfield, S. \& Claxton-Oldfield, J. (2008b). Keeping hospice palliative care volunteers on board: Dealing with issues of attrition, stress, and retention. Indian Journal of Palliative Care, 14, 30-37.

Delaloye, S. (2007). Des bénévoles d'accompagnement dans des unités de soins aigus. Palliative.ch, 2, 20-23.

Doyle, D. (2002). Volunteers in hospice and palliative care: A handbook for volunteer service managers. Oxford: Oxford University Press.

Ernstmann, N., Neumann, M., Ommen, O., et al. (2009). Determinants and implications of cancer patients' psychosocial needs. Supportive Care in Cancer, 17, 1417-1423.

Field, D. \& Johnson, I. (1993). Satisfaction and change: A survey of volunteers in a hospice organisation. Social Science \& Medicine, 36, 1625-1633.

Fusco-Karmann, C. \& Tinini, G. (2001). A review of the volunteer movement in EAPC countries. European Journal of Palliative Care, 8, 199-202.

Gagnon, E. \& Sévigny, A. (2000). Permanence et mutations du monde bénévole. Recherches Sociographiques, 41, 529-44.

Guirguis-Younger, M. \& Grafanaki, S. (2008). Narrative accounts of volunteers in palliative care settings. American Journal of Hospice \& Palliative Care, 25, 16-23.

Guirguis-Younger, M., Kelley, M.L. \& McKee, M. (2005). Professionalization of hospice volunteer practices: What are the implications? Palliative \& Supportive Care, 3, 143-144.

Handy, F. \& Srinivasan, N. (2002). Les bénévoles en milieu hospitalier: Une ressource changeante et importante. Toronto: Centre canadien de philanthropie.

Künzi, D. (2007). Accompagner la vie, accompagner la souffrance: Une analyse en milieu hospitalier. Paris: L'Harmattan.

Künzi, D. (2011). Le bénévolat en unité de soins: Un bol d'air fort apprécié. Soins Infirmiers, 104, 47-49.

Landry-Dattee, N. (2000). A link between medical staff and the world at large. European Journal of Palliative Care, $7,14-17$.

Macvean, M.L., White, V.M., Pratt, S., et al. (2007). Reducing the unmet needs of patients with colorectal cancer: A feasibility study of The Pathfinder Volunteer Program. Supportive Care in Cancer, 15, 293-299.

Mays, N. \& Pope, C. (1995). Qualitative research: Observational methods in health care settings. BMJ, 311, $182-184$

McKinnon, M.M. (2002). The participation of volunteers in contemporary palliative care. Australian Journal of Advanced Nursing, 19, 38-44.

Merrell, J. (2000). Ambiguity: Exploring the complexity of roles and boundaries when working with volunteers in well woman clinics. Social Science \& Medicine, 51, 93-102.

Moadel, A., Morgan, C., Fatone, A., et al. (1999). Seeking meaning and hope: Self-reported spiritual and existential needs among an ethnically diverse cancer patient population. Psycho-Oncology, 8, 378-385.

Morris, S., Wilmot, A., Hill, M., et al. (2013). A narrative literature review of the contribution of volunteers in end-of-life care services. Palliative Medicine, 27(5), 428-436.

Mouniqua, A. (2006). Le rôle du bénévolat à l'Institut Gustave-Roussy à la consultation de soins palliatifs. European Journal of Palliative Care, 13, 169-170.

Musick, M.A. \& Wilson, J. (2003). Volunteering and depression: The role of psychological and social resources in different age groups. Social Science \& Medicine, 56 , 259-269.

Nissim, R., Regehr, M., Rozmovits, L., et al. (2009). Transforming the experience of cancer care: A qualitative study of a hospital-based volunteer psychosocial support service. Supportive Care in Cancer, 17, 801-809.

Papadaniel, Y. (2010). Accompagnement en fin de vie et solidarité: Quelques pistes de réflexions autour du bénévolat dans les soins palliatifs. Revue Internationale de Soins Palliatifs, 25, 19-23. 
Pope, C., Ziebland, S. \& Mays, N. (2000). Qualitative research in health care: Analysing qualitative data. BMJ, 320, 114-116.

Sévigny, A., Paquet, S. \& Frappier, A. (2009). Proximité et identité: La question du bénévolat revisitée. Réciproques, 115-124.

Sévigny, A., Robin Cohen, S., Dumont, S., et al. (2010). Making sense of health and illness in palliative care: Volunteers' perspectives. Palliative \& Supportive Care, 8(3), 325-334.
Sterchi-Noden, C. (2007). Freiwillige Begleiterinnen: Ihre Rolle in der ambulanten Palliativen Versorgung. Palliative.ch, 2, 5-8.

St.-Pierre, M., Sévigny, A., Gauthier, J.-B., et al. (2009). Une nouvelle approche pour la gestion de l'intégration dans le système de santé: Le cas des bénévoles et des professionnels. Management et Avenir, 6, 177-189.

Wilson, D.M., Justice, C., Thomas, R., et al. (2005). End-oflife care volunteers: A systematic review of the literature. Health Services Management Research , 18, 244-257. 